\title{
Physical Activity and Quality of Life among Adults with Paraplegia in Odisha, India
}

*Shankar Ganesh and Chittaranjan Mishra

$$
\text { النشاط البدي وجودة الحياة بين البالغين المصابين بالشلل السفلي في أوديشا }
$$

شانكر جانيش و شيتارانجان ميشرا

ABSTRACT: Objectives: The complete rehabilitation of patients with spinal cord injuries (SCI) comprises both physical and psychosocial factors. This study therefore aimed to assess physical activity and quality of life (QOL) among paraplegic patients with SCI in Odisha, India. Methods: This cross-sectional prospective study was conducted between March 2010 and December 2013. All paraplegic patients treated at the Swami Vivekanand National Institute of Rehabilitation Training \& Research in Odisha, India, during the study period who met the inclusion criteria were invited to participate in the study $(n=364)$. Structured face-to-face interviews were held with participants and QOL and physical activity were assessed using the abbreviated World Health Organization QOL instrument and the Physical Activity Scale for Individuals with Physical Disabilities, respectively. Results: A total of 84 people participated in the study (response rate: $23.1 \%$ ). The mean age was $32.54 \pm 10.75$ years and $90.5 \%$ of the participants were male. Participants had a low mean metabolic equivalent score (18.18 \pm 10.68 hours/day). Additionally, low mean scores were noted for the physical health, psychological well-being, social relationships and environment QOL domains ( $49.76 \pm 18.74,48.57 \pm 17.04,57.88 \pm 17.04$ and $49.85 \pm 17.77$, respectively). There was a strong positive association between levels of physical activity and all QOL domains $(P<0.050)$. Physical activity and employment status were significant predictors of all QOL domains $(P<0.001)$. Conclusion: Low physical activity levels and QOL were noted among the paraplegic subjects. Interventions promoting physical activity and employment may help to improve QOL among this patient group.

Keywords: Paraplegia; Spinal Cord Injuries; Quality of Life; Physical Activity; Rehabilitation; India.

الملخص: الهدف: إعادة التأهيل الكاملة لمرض إصابات الحبل الشوكي تتألف من عوامل بدنية ونفسية. تهدف هذه الهـات الدراسة إلى تقييم

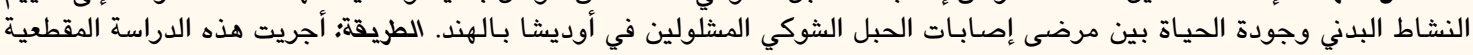

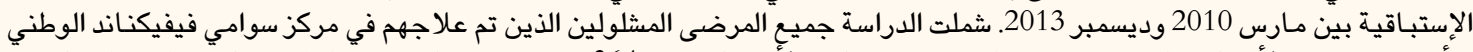

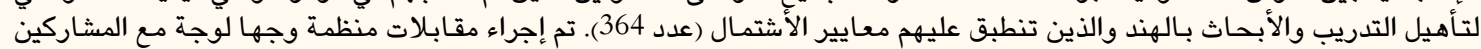

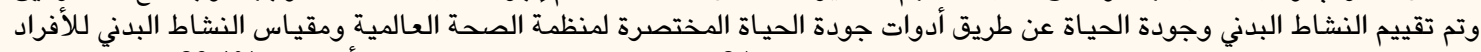

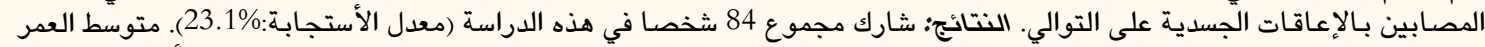

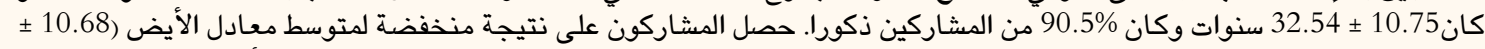

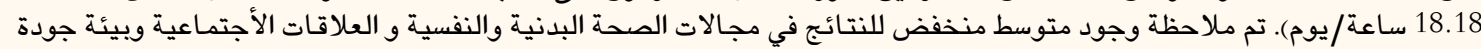

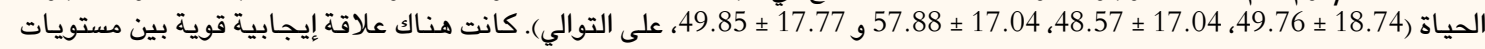

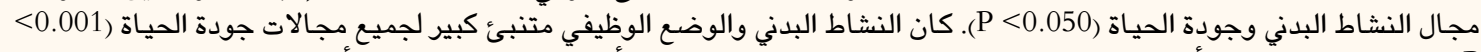

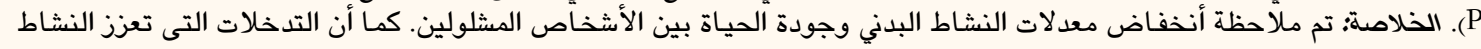

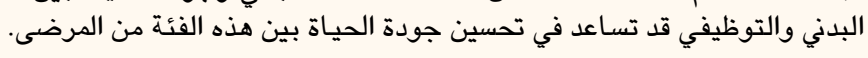

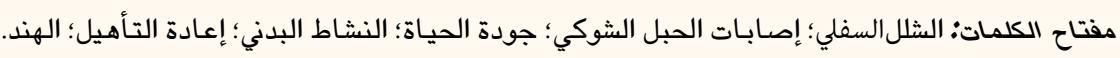

\footnotetext{
Advances IN KNOWLedge

Low physical activity levels and quality of life (QOL) were noted among the studied individuals with spinal cord injuries (SCI) in Odisha, India.

The study found a strong positive association between physical activity and all domains of QOL. Furthermore, physical activity and employment status were significant predictors of all QOL domains.

\section{Application to Patient Care}

The identification of variables affecting QOL is necessary to inform rehabilitation protocols for patients with SCI. Rehabilitation measures should address emotional, social and cognitive factors as well as physical rehabilitation in order to achieve better QOL for these patients.

As the QOL of patients with SCI in the current study was found to be influenced by physical activity and employment status, initiatives to promote physically active lifestyles and re-employment among the SCI population should be encouraged.
} 
A DVANCES IN THE MEDICAL MANAGEMENT of spinal cord injuries (SCI) have reduced the severity of this disability and increased patient longevity. ${ }^{1}$ Following the completion of inpatient rehabilitation, most patients with SCI are discharged and are expected to resume their lives and find ways of coping with their disability. ${ }^{2}$ However, health and wellbeing are best understood in terms of a combination of biological, psychological and social factors. As certain disabilities are permanent, including those associated with SCI, there is a need to identify factors affecting well-being which can be influenced by the rehabilitation team. Traditional health indicators provide a measure of the impact of disease but do not assess quality of life (QOL) in the context of an individual's culture, value systems, goals, expectations, standards and concerns. ${ }^{3}$ Wilson et al. stated that QOL should be routinely assessed among individuals with SCI along with neurological and functional outcomes. ${ }^{4}$ Subjective QOL is considered by some researchers to be the only relevant measure of QOL among individuals with SCI as it reflects their own perception of their well-being. ${ }^{5}$ The inclusion of QOL assessments in healthcare will promote a holistic treatment approach and encourage healthcare professionals to account for the personal perceptions and values of their patients. Hence, the evaluation of QOL is a crucial issue for future national health planning.

Very few studies have evaluated the QOL of SCI patients in India, where the estimated SCI prevalence is 236 per million. ${ }^{6}$ Gupta et al. found that patients with neurological illnesses, including SCI, reported impaired QOL in all domains of life; moreover, the social relationships domain of QOL was noted to adversely affect functional abilities. ${ }^{7}$ Singh et al. reported that gender, employment, mobility, autonomy, partner relations and social adjustment were associated with fair-to-good QOL scores among individuals with SCI in northern India. ${ }^{8}$ Tasiemski et al. compared life satisfaction and life values among SCI-affected individuals living in India, Vietnam and Sri Lanka; no significant relationships were observed between these variables. ${ }^{9}$ In an international cross-sectional study, Geyh et al. examined the QOL of SCI patients across six countries using five satisfaction items from the World Health Organization QOL (WHOQOL) assessment. ${ }^{10}$ The results indicated inter-country QOL differences that could not be explained by differences in demographic or lesion-related characteristics; future research in this area was hence recommended. ${ }^{10}$ As little is known about the subjective differences in QOL among SCI patients with different backgrounds, this study aimed to determine physical activity levels and QOL among SCI patients in Odisha, India, and identify relationships between demographic/clinical data, physical activity levels and QOL.

\section{Methods}

This cross-sectional study was conducted between March 2010 and December 2013 at the Swami Vivekanand National Institute of Rehabilitation Training \& Research in Odisha. During this period, a total of 364 paraplegic in- or outpatients with SCI of at least one year's duration were invited to participate in the study. As physical function, independence and physical well-being is known to affect the QOL of quadriplegic patients to a greater extent than paraplegic patients, the study was limited to patients with paraplegia. ${ }^{11}$ Patients with thoracic and lumbar injuries and without mental health problems or medication usage that might affect their decisionmaking skills were included. The exclusion criteria included patients with traumatic brain injuryassociated SCI, brachial plexus injuries and/or fractures of the extremities and systemic medical diseases that would restrict physical activity. Individuals who met these criteria were invited to participate in the study. Data were collected using surveys in combination with interviews to ensure uniformity in the research process.

Each subject participated in a structured faceto-face interview which lasted an average of 45 minutes. The interviews were conducted in Oriya, the regional dialect spoken in Odisha. All questions were translated from English to Oriya by two translators using back-translation methods. Interviews were conducted by one researcher while another monitored the proceedings. Demographic data and information on QOL and physical activity was collected during the interviews using questionnaires. The questionnaires were filled out by the researcher who conducted the interviews due to the lack of reading literacy amongst some of the participants. At the end of each interview, the interviewee was given the opportunity to clarify any doubts or ask questions.

A custom-made Oriya-language survey with closeended questions was used to collect demographic data from participants, including age, gender, time since injury, marital status, level of education and employment status. For the purpose of the study, participants were categorised into age groups of fiveyear intervals. Education level was recorded on a scale from $1-4$ ( 1 = no education, 2 = primary education, 3 = secondary education and $4=$ university-level education). The employment and marital statuses of the participants before and after their injury were also noted. For statistical analysis, only post-injury 
Table 1: Demographic characteristics of individuals with spinal cord injuries in Odisha, India $(\mathrm{N}=84)$

\begin{tabular}{lc} 
Characteristic & $\mathbf{n}(\%)$ \\
Gender & \\
Male & $76(90.5)$ \\
Female & $8(9.5)$ \\
Mean age in years (range) & $32.54 \pm 10.75(15-60)$ \\
Marital status & \\
Unmarried & $40(47.6)$ \\
Married & $44(52.4)$ \\
Education level & \\
No education & $12(14.3)$ \\
Primary & $10(11.9)$ \\
Secondary & $28(33.3)$ \\
University-level & $34(40.5)$ \\
Employment status & \\
Employed & $12(14.3)$ \\
Unemployed & $(12-84)$ \\
Paraplegia severity* & $78(92.1)$ \\
A & \\
B & $40(47.6)$ \\
C & \\
D & \\
(range) & $(19.0)$ \\
\hline
\end{tabular}

"Paraplegia was classified as either complete (categories A and B) or incomplete (categories $C$ and D) according to the American Spinal Injury Association Impairment Scale. ${ }^{12}$

values were considered. Paraplegia was classified as either complete (categories A and B) or incomplete (categories $C$ and D) according to the American Spinal Injury Association Impairment Scale (AIS). ${ }^{12}$

Physical activity levels were measured using the Physical Activity Scale for Individuals with Physical Disabilities (PASIPD), which assesses the long-term effects of SCI on the health, functional ability and independence of persons with SCI. ${ }^{13}$ This scale has been found to have good test-retest reliability and criterion validity. ${ }^{14}$ Participants' QOL was assessed using the abbreviated version of the WHOQOL assessment (WHOQOL-BREF). ${ }^{3}$ This international crossculturally comparable instrument measures QOL across four domains: physical health (pain/discomfort, energy/fatigue and sleep/rest), psychological wellbeing (body image/appearance, negative feelings, positive feelings, self-esteem and thinking/learning/ memory/concentration), social relationships (person- al relationships, social support and sexual activity) and environment (financial resources, freedom/physical safety/security, accessibility/quality of health/social care, home environment, opportunities for acquiring new information/skills, participation in/opportunities for recreation/leisure activities, physical environment e.g. pollution/noise/traffic/climate and transport). ${ }^{3}$ The WHOQOL-BREF assessment is currently the most accepted and established instrument to assess QOL among individuals with SCI. ${ }^{15}$ The instrument has shown good differentiation, content validity and testretest reliability. ${ }^{3}$ Based on an individual's responses to the questionnaire, QOL is scored between zero (poor QOL) and 100 (high QOL). In addition, domain scores correlate at approximately 0.9 with those of the full version of the WHOQOL instrument. ${ }^{3}$

Data were analysed using the Statistical Package for the Social Sciences (SPSS), Version 16 (IBM Corp., Chicago, Illinois, USA). A Pearson product-moment correlation coefficient analysis was used to identify relationships between QOL and physical activity, time since injury, age, gender, marital status, employment status, paraplegia severity and educational level. A multiple linear regression analysis with backward elimination was used to determine the significance of eight predictors (age, gender, education level, paraplegia severity, time since injury, employment status, physical activity and marital status) of QOL. For all analyses, a $P$ value of $<0.050$ was considered significant.

Ethical approval for this study was granted from the Ethics Committee of the Swami Vivekanand National Institute of Rehabilitation Training \& Research. Participation in the study was voluntary and informed consent was obtained from each participant. Due to the sensitive nature of the study, all participants were provided with the telephone number of the institute's clinical psychologist for counselling services.

\section{Results}

A total of 84 individuals with SCI participated in the study (response rate: 23.1\%). Of these, there were 76 men $(90.5 \%)$ and eight women (9.5\%). The mean age was $32.54 \pm 10.75$ years (range: $15-60$ years old). All of the participants used mechanical wheelchairs daily, were independent and needed no nursing. The post-injury employment rate of the participants was $7.1 \%$ and the average time since the onset of their injuries was $26.73 \pm 23.94$ months. The descriptive characteristics of the participants are reported in Table 1.

Participants reported a mean metabolic equivalent score of $18.18 \pm 10.68$ hours/day out of a possible 

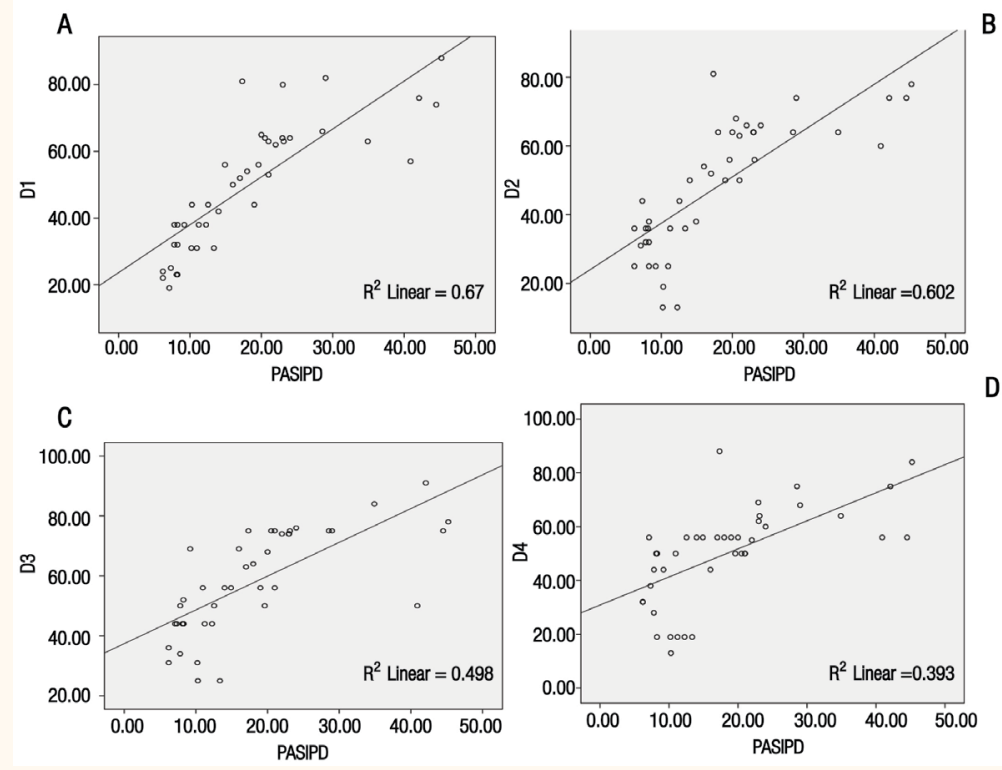

Figure 1A-D: Scatter plots showing the relationship between physical activity* and (A) physical health, (B) psychological well-being, (C) social relationships and (D) environment domains of quality of life ${ }^{\dagger}$ among individuals with spinal cord injuries in Odisha, India $(\mathrm{N}=84)$.

*Physical activity was assessed using the Physical Activity Scale for Individuals with Physical Disabilities. ${ }^{13}{ }^{\dagger}$ Quality of life (QOL) was assessed using the abbreviated version of the World Health Organization QOL measure."

199.5 hours/day, suggesting that patients were physically active for a few hours during the day and a few days during the week. In the physical health, psychological well-being, social relationships and environment QOL domains, participants had mean scores of $49.76 \pm 18.74,48.57 \pm 17.04,57.88 \pm 17.04$ and $49.85 \pm 17.77$, respectively.

There was a strong association between levels of physical activity and the physical health $(\mathrm{r}=0.819$; $P<0.050)$, psychological well-being $(r=0.776$; $P<0.050)$, social relationships $(\mathrm{r}=0.706 ; P<0.050)$ and environment $(\mathrm{r}=0.627 ; P<0.050)$ domains of $\mathrm{QOL}$ [Figure 1]. A weak correlation was found between employment status and the physical health $(\mathrm{r}=0.262$; $P<0.050)$, psychological well-being $(\mathrm{r}=0.277 ; P<0.050)$ and environment $(\mathrm{r}=0.332 ; P<0.050)$ domains of
QOL. No correlation was found between employment status and the social relationship domain $(r=0.144$; $P>0.050$ ). There were moderate and weak associations between the time since injury and the physical health ( $\mathrm{r}=0.456 ; P<0.050)$ and psychological well-being ( $\mathrm{r}=0.277 ; P<0.050)$ domains of QOL, respectively. However, there was no significant relationship between the time since injury and the social relationships and environment domains. Paraplegia severity according to AIS scores was significantly related to all domains of QOL ( $\mathrm{r}=0.300 ; P<0.050)$. No association was found between QOL and age, gender, marital status or educational level [Table 2].

According to the multiple regression analysis, none of the predictors of QOL exceeded Bonferroniadjusted critical values [Table 3]. Time since injury

Table 2: Correlations between quality of life* and demographic characteristics and physical activity ${ }^{\dagger}$ among individuals with spinal cord injuries in Odisha, India $(\mathrm{N}=84)$

$\begin{array}{lcccccccc}\text { QOL domain } & \text { Age } & \text { Gender } & \begin{array}{c}\text { Time since } \\ \text { injury }\end{array} & \begin{array}{c}\text { Paraplegia } \\ \text { severity }\end{array} & \begin{array}{c}\text { Employment } \\ \text { status }\end{array} & \begin{array}{c}\text { Marital } \\ \text { status }\end{array} & \begin{array}{c}\text { Education } \\ \text { level }\end{array} & \begin{array}{c}\text { Physical } \\ \text { activity }\end{array} \\ \text { Physical health } & 0.109 & -0.157 & 0.456^{\S} & 0.561^{\S} & 0.267 & 0.164 & 0.033 & 0.819^{\S} \\ \text { Psychological well-being } & 0.142 & -0.019 & 0.277^{\S} & 0.358^{\S} & 0.277 & 0.156 & 0.019 & 0.776^{\S} \\ \text { Social relationships } & 0.032 & -0.500 & 0.195 & 0.466^{\S} & 0.144 & 0.007 & 0.138 & 0.706^{\S} \\ \text { Environment } & 0.073 & -0.048 & 0.198 & 0.330^{\S} & 0.332 & 0.022 & 0.098 & 0.627^{\S}\end{array}$

$Q O L=$ quality of life.

"QOL was assessed using the abbreviated version of the World Health Organization QOL measure. ${ }^{+}$Physical activity was assessed using the Physical Activity Scale for Individuals with Physical Disabilities. ${ }^{13}{ }^{7}$ Paraplegia was classified as either complete (categories A and B) or incomplete (categories $C$ and D) according to the American Spinal Injury Association Impairment Scale. ${ }^{12}{ }^{\mathbb{P}} P<0.001 .{ }^{9} P<0.050$. 
Table 3: Multiple regression analysis of variables predicting quality of life domains* among individuals with spinal cord injuries in Odisha, India $(\mathrm{N}=84)$

\begin{tabular}{|c|c|c|c|c|}
\hline Variable & B & SE B & B & $P$ value \\
\hline \multicolumn{4}{|l|}{ Physical health } & $<0.050$ \\
\hline Constant & 11.833 & 10.747 & - & \\
\hline Age & -0.214 & 0.882 & -0.024 & \\
\hline Gender & -2.954 & 4.839 & -0.042 & \\
\hline $\begin{array}{l}\text { Paraplegia } \\
\text { severity }\end{array}$ & 2.640 & 3.081 & 0.071 & \\
\hline $\begin{array}{l}\text { Time since } \\
\text { injury }\end{array}$ & 0.139 & 0.053 & 0.182 & \\
\hline Marital status & 0.183 & 4.086 & 0.005 & \\
\hline $\begin{array}{l}\text { Employment } \\
\text { status }\end{array}$ & 11.399 & 5.283 & 0.161 & \\
\hline $\begin{array}{l}\text { Physical } \\
\text { activity }^{\dagger}\end{array}$ & 1.242 & 0.162 & 0.679 & \\
\hline Education level & -0.739 & 1.242 & -0.042 & \\
\hline \multicolumn{4}{|c|}{ Psychological well-being } & $<0.050$ \\
\hline Constant & -17.585 & 11.844 & - & \\
\hline Age & -0.261 & 0.972 & -0.029 & \\
\hline Gender & 6.552 & 5.333 & 0.094 & \\
\hline $\begin{array}{l}\text { Paraplegia } \\
\text { severity }\end{array}$ & 8.780 & 3.395 & 0.239 & \\
\hline $\begin{array}{l}\text { Time since } \\
\text { injury }\end{array}$ & -0.040 & 0.059 & -0.053 & \\
\hline Marital status & 1.347 & 4.503 & 0.037 & \\
\hline $\begin{array}{l}\text { Employment } \\
\text { status }\end{array}$ & 14.770 & 5.822 & 0.211 & \\
\hline $\begin{array}{l}\text { Physical } \\
\text { activity }^{\dagger}\end{array}$ & 1.107 & 0.179 & 0.611 & \\
\hline Education level & 0.269 & 1.368 & 0.015 & \\
\hline \multicolumn{4}{|c|}{ Social relationships } & $<0.050$ \\
\hline Constant & 28.532 & 12.371 & - & \\
\hline Age & -0.143 & 1.015 & -0.018 & \\
\hline Gender & -1.698 & 5.570 & -0.027 & \\
\hline $\begin{array}{l}\text { Paraplegia } \\
\text { severity }\end{array}$ & 4.873 & 3.546 & 0.148 & \\
\hline $\begin{array}{l}\text { Time since } \\
\text { injury }\end{array}$ & -0.032 & 0.061 & -0.048 & \\
\hline Marital status & -3.421 & 4.703 & -0.104 & \\
\hline $\begin{array}{l}\text { Employment } \\
\text { status }\end{array}$ & 6.387 & 6.081 & 0.102 & \\
\hline $\begin{array}{l}\text { Physical } \\
\text { activity }^{\dagger}\end{array}$ & 0.899 & 0.187 & 0.554 & \\
\hline Education level & -2.798 & 1.429 & -0.179 & \\
\hline
\end{tabular}

\begin{tabular}{|c|c|c|c|c|}
\hline Environment & & & & $<0.050$ \\
\hline Constant & -9.140 & 12.371 & - & \\
\hline Age & -0.487 & 1.075 & -0.057 & \\
\hline Gender & -4.849 & 5.898 & -0.072 & \\
\hline $\begin{array}{l}\text { Paraplegia } \\
\text { severity }\end{array}$ & 2.079 & 3.755 & 0.059 & \\
\hline $\begin{array}{l}\text { Time since } \\
\text { injury }\end{array}$ & -0.031 & 0.065 & -0.043 & \\
\hline Marital status & 2.956 & 4.981 & 0.085 & \\
\hline $\begin{array}{l}\text { Employment } \\
\text { status }\end{array}$ & 9.582 & 6.440 & 0.143 & \\
\hline $\begin{array}{l}\text { Physical } \\
\text { activity }^{\dagger}\end{array}$ & 0.759 & 0.198 & 0.438 & \\
\hline Education level & 1.527 & 1.514 & 0.092 & \\
\hline
\end{tabular}

$S E=$ standard error

"Quality of life (QOL) was assessed using the abbreviated version of the World Health Organization QOL measure. ${ }^{3}$ Physical activity was assessed using the Physical Activity Scale for Individuals with Physical Disabilities. ${ }^{13}$

( $\mathrm{t}=3.274 ; P<0.001)$, employment status $(\mathrm{t}=2.383$;

$P<0.001)$ and physical activity $(\mathrm{t}=12.550 ; P<0.001)$ were strong predictors for the physical health domain components of QOL. Paraplegia severity $(\mathrm{t}=2.215$; $P<0.050)$, employment status $(\mathrm{t}=3.458 ; P<0.001)$ and physical activity $(\mathrm{t}=7.778 ; P<0.001)$ were strong predictors of the psychological well-being domain components of QOL. Marital status ( $\mathrm{t}=-2.482$; $P<0.001)$, employment status $(\mathrm{t}=1.927 ; P<0.001)$ and physical activity $(\mathrm{t}=9.340 ; P<0.001)$ significantly predicted the social relationships domain of QOL. Employment status ( $\mathrm{t}=3.480 ; P<0.001)$ and physical activity $(\mathrm{t}=7.563 ; P<0.001)$ were the two predictors found to influence the environment domain of QOL.

\section{Discussion}

Among the studied individuals with SCI, very low mean QOL scores were reported in comparison to normal mean scores for the physical health $(49.76 \pm 18.74$ versus $73.50 \pm 18.10)$, psychological well-being (48.57 \pm 17.04 versus $70.60 \pm 14.00$ ), social relationships (57.88 \pm 17.04 versus $71.50 \pm 18.20)$ and environment (49.85 \pm 17.77 versus $75.10 \pm 13.00$ ) domains. ${ }^{16}$ The results of the current study are therefore consistent with previous research reporting poor QOL in patients with SCI. de França et al. evaluated QOL among 47 SCI patients (mean age: 42.95 years) using the WHOQOL-BREF and obtained mean scores of 58.59, 63.82, 68.79 and 55.20 for the physical health, psychological well-being, social relationships and environment domains, respectively. ${ }^{17}$

A statistically significant and strong positive association between physical activity and all domains 
of QOL was observed among the studied sample of SCI patients. The mean metabolic equivalent score of the participants was suggestive of a low level of physical activity among SCI patients in Odisha, indicating that patients were physically active for fewer hours per day and fewer days per week than highly-active individuals with physical disabilities $(36.34 \pm 15.28) .{ }^{18}$ Another study found that higher PASIPDscores $(22.5 \pm 14.8)$ were reported by individuals with physical disabilities who rated their level of physical activity as active/extremely active. ${ }^{13}$ Stevens et al. also demonstrated reduced physical activity among individuals with SCI. ${ }^{19}$ Low physical activity has been found to correlate strongly with QOL in patients with SCI. ${ }^{20}$ Previous studies have found that people with disabilities are less likely to engage in physically active lifestyles than those without disabilities. ${ }^{21,22}$ Reasons for the low levels of physical activity among participants in the current study were beyond the scope of this study. However, architectural barriers (i.e. a lack of transportation facilities or wheelchairaccessible environments), societal attitudes, climate, logistical issues (i.e. problems with wheelchairs), loss of motor function and a lack of knowledge about how to engage in physical activity may play decisive roles, along with psychological factors.

Employment status was found to be a strong predictor of all domains of QOL in the current study. Critically, participants had a very low postinjury employment rate. Unemployment and low income may result in financial difficulties, which is an important factor affecting the QOL of those with SCI. ${ }^{23}$ Financial hardships may also be associated with emotional problems. ${ }^{24}$ Harrison et al. found that only $8 \%$ of 222 SCI patients were employed following their injuries..$^{25}$ Another study showed a considerable drop in employment rates after SCI. ${ }^{26}$ These studies indicated that unemployment rates were 10-fold higher among SCI patients compared with the general population. ${ }^{25,26}$ Access to place of work, employer attitudes and patients' beliefs in their own abilities may influence the decision to resume employment following SCI. ${ }^{26}$ Singh et al. found that employment status was associated with a higher QOL among those with SCI living in India. ${ }^{8}$ Chapin et al. reported that SCI patients who had been successfully rehabilitated and were employed had a significantly higher QOL in all four domains. ${ }^{27}$

In the current study, physical activity and employment status were found to strongly predict scores in the physical health domain of QOL. Reduced physical activity among individuals with SCI may be related to changes in metabolism. ${ }^{28}$ Among paraplegic individuals, $25 \%$ have a maximum oxygen consumption of $15 \mathrm{~mL} / \mathrm{kg} /$ minute; the normal range is $34-61 \mathrm{~mL} / \mathrm{kg} / \mathrm{minute}$ for males and $30-42 \mathrm{~mL} / \mathrm{kg} /$ minute for females. ${ }^{29}$ This reduced maximum oxygen consumption is inadequate to meet the requirements of independent living. ${ }^{29}$ Furthermore, the total caloric intake per day for individuals with SCI is lower than that of the general population. ${ }^{28}$ These factors may result in increased fatigue during work-related or daily living activities.

Several studies have shown no relationship between the time since injury and QOL among individuals with SCI. ${ }^{30,31}$ In contrast, the current study identified a strong predictive relationship between the time since injury and the physical health domain of QOL. This could be attributed to a gradual reduction in pain and improvement in function over time. In a crosssectional study, Saadat et al. compared the healthrelated QOL of veterans and non-veterans with SCI in Iran and noted that better health-related QOL was associated with a longer period of time since the injury. ${ }^{32}$

$\mathrm{Hu}$ et al. found a significant difference between patients with complete and incomplete paraplegia with regards to the environment domain of QOL. ${ }^{33}$ However, the results of the current study indicated that the severity of paraplegia significantly predicted and was associated with the psychological wellbeing domain of QOL. The researchers hypothesise that this finding is a result of low self-esteem and negative feelings related to a lack of control over the environment due to the severity of the disability. Selfefficacy and self-esteem have been found to correlate highly with participation and contribute to a better understanding of functioning, disability and health in those with SCI. ${ }^{34}$ Access to the environment has been shown to be related to neurological status, with the environment more accessible to individuals with mild impairment than to those with severe impairment. ${ }^{35}$

In the current study, marital status was a significant predictor of the social relationships domain of QOL. Married subjects may have been less satisfied with their lives, more anxious about their sex lives and felt pressured by their inability to function normally in the household. Reasons for not wanting or not having the courage to be sexually intimate may be related to physical problems, low sexual desire, low self-esteem and feelings of being unattractive. ${ }^{36}$

The findings of this study indicate that rehabilitation should aim to improve QOL among individuals with SCI. This may be done by facilitating shared clinical decision-making to help individuals with SCI to achieve their preferences, adjust to their disability, improve their interpersonal relationships and reintegrate within the community. The development of interventions and programmes to increase levels of 
physical activity may also be effective in improving QOL among this population. Marital counselling, vocational rehabilitation training and creating job opportunities for those affected by SCI are important components of comprehensive rehabilitation programmes.

There are several potential limitations to this study. The percentage of female participants was low, which may have adversely influenced the effect of gender on QOL. In addition, the study was restricted to participants who had undergone rehabilitation after SCI of at least one year's duration. This may have affected the results; a longitudinal multicentre study found that individuals with SCI reported changes in the physical health domain of QOL during the first two years post-injury. ${ }^{37}$ In the current study, secondary complications of SCI (including pain, urinary tract infections, chronic illness and changes in bowel and bladder function) were not considered. Furthermore, the QOL instrument considers the level of function only at the time of assessment. Despite these limitations, the present study fulfilled its objectives in identifying key predictors of QOL among paraplegic individuals in a developing country.

\section{Conclusion}

Rehabilitation for individuals with SCI should focus on aspects of all QOL domains, including physical health, psychological well-being, social relationships and environment. A strong positive correlation between physical activity and employment status with all domains of QOL was found among the studied group of individuals with SCI from Odisha. In light of these findings, programmes to increase physical activity and employment status among SCI patients are recommended.

\section{ACKNOWLEDGEMENTS}

A poster presentation of this study was displayed at the $53^{\text {rd }}$ International Spinal Cord Society Scientific Meeting in Maastricht, the Netherlands, in September 2014. An abstract of the poster was published in the Abstracts booklet for this meeting.

\section{CONFLICT OF INTEREST}

The authors declare no conflicts of interest.

\section{References}

1. Trieschmann RB. Spinal Cord Injuries: Psychological, social, and vocational rehabilitation. 2nd ed. New York, USA: Demos Publications, 1998. Pp. 1-24.
2. Forchheimer M, Tate DG. Enhancing community re-integration following spinal cord injury. NeuroRehabilitation 2004; 19:103-13.

3. The World Health Organization Quality of Life Group Development of the World Health Organization WHOQOLBREF quality of life assessment. Psychol Med 1998; 28:551-8. doi: $10.1017 /$ S0033291798006667.

4. Wilson JR, Hashimoto RE, Dettori JR, Fehlings MG. Spinal cord injury and quality of life: A systematic review of outcome measures. Evid Based Spine Care J 2011; 2:37-44. doi: 10.1055/ S-0030-1267085.

5. Dijkers M. Quality of life after spinal cord injury: A meta analysis of the effects of disablement components. Spinal Cord 1997; 35:829-40. doi: 10.1038/sj.sc.3100571.

6. Hagen EM, Rekand T, Gilhus NE, Grønning M. Traumatic spinal cord injuries: Incidence, mechanisms and course. Tidssk Nor Laegeforen 2012; 132:831-7. doi: 10.4045/tidsskr.10.0859.

7. Gupta A, Deepika S, Taly AB, Srivastava A, Surender V, Thyloth M. Quality of life and psychological problems in patients undergoing neurological rehabilitation. Ann Indian Acad Neurol 2008; 11:225-30. doi: 10.4103/0972-2327.44557.

8. Singh R, Dhankar SS, Rohilla R. Quality of life of people with spinal cord injury in Northern India. Int J Rehabil Res 2008; 31:247-51. doi: 10.1097/MRR.0b013e3282fb7d25.

9. Tasiemski T, Priebe MM, Wilski M. Life satisfaction and life values in people with spinal cord injury living in three Asian countries: A multicultural study. J Spinal Cord Med 2013; 36:118-26. doi: 10.1179/2045772312Y.0000000074.

10. Geyh S, Ballert C, Sinnott A, Charlifue S, Catz A, D'Andre Greve JM, et al. Quality of life after spinal cord injury: A comparison across six countries. Spinal Cord 2013; 51:322-6. doi: $10.1038 /$ sc.2012.128.

11. Manns PJ, Chad KE. Components of quality of life for persons with a quadriplegic and paraplegic spinal cord injury. Qual Health Res 2001; 11:795-811. doi: 10.1177/10497320112911 9541.

12. Spinal Cord Injury Research Evidence Project. American Spinal Injury Association Impairment Scale (AIS): International standards for neurological classification of spinal cord injury. From: www.scireproject.com/outcome-measures-new/americ an-spinal-injury-association-impairment-scale-aisinternational-standards Accessed: Oct 2015

13. Washburn RA, Zhu W, McAuley E, Frogley M, Figoni SF. The Physical Activity Scale for Individuals with Physical Disabilities Development and evaluation. Arch Phys Med Rehabil 2002; 83:193-200.

14. van der Ploeg HP, Streppel KR, van der Beek AJ, van der Woude LH, Vollenbroek-Hutten M, van Mechelen W. The Physical Activity Scale for Individuals with Physical Disabilities: Test-retest reliability and comparison with an accelerometer. Phys Act Health 2007; 4:96-100.

15. Hill MR, Noonan VK, Sakakibara BM, Miller WC; SCIRE Research Team. Quality of life instruments and definitions in individuals with spinal cord injury: A systematic review. Spinal Cord 2010; 48:438-50. doi: 10.1038/sc.2009.164.

16. Hawthorne G, Herrman H, Murphy B. Interpreting the WHOQOL-Brèf: Preliminary Population norms and effect sizes. Soc Indic Res 2006; 77:37-59. doi: 10.1007/s11205-0055552-1.

17. de França IS, Coura AS, de França EG, Basílio NN, Souto RQ. [Quality of life adults with spinal cord injury: A study using the WHOQOL-BREF.] Rev Esc Enferm USP 2011; 45:1346-71. doi: 10.1590/S0080-62342011000600013.

18. Giacobbi PR Jr, Stancil M, Hardin B, Bryant L. Physical activity and quality of life experienced by highly active individuals with physical disabilities. Adapt Phys Activ Q 2008; 25:189-207. 
19. Stevens SL, Caputo JL, Fuller DK, Morgan DW. Physical activity and quality of life in adults with spinal cord injury. J Spinal Cord Med 2008; 31:373-8.

20. Dijkers MP. Correlates of life satisfaction among persons with spinal cord injury. Arch Phys Med Rehabil 1999; 80:867-76. doi: 10.1016/S0003-9993(99)90076-X.

21. Rimmer JH. Health promotion for people with disabilities: The emerging paradigm shift from disability prevention to prevention of secondary conditions. Phys Ther 1999; 79:495-502.

22. Rimmer JH. Health promotion for individuals with disabilities The need for a transitional model in service delivery. Dis Manag Health Outcomes 2002; 10:337-43. doi: 10.2165/00115677200210060-00002.

23. Tasiemski T, Nielsen S, Wilski M. Quality of life in people with spinal cord injury: Earthquake survivors from Sichuan Province in China. Asia Pac Disabil Rehabil J 2010; 21:28-36.

24. Migliorini CE, New PW, Tonge BJ. Comparison of depression, anxiety and stress in persons with traumatic and non-traumatic post-acute spinal cord injury. Spinal Cord 2009; 47:783-8. doi: $10.1038 / \mathrm{sc} .2009 .43$

25. Harrison C, Kuric J. Community reintegration of SCI persons: Problems and perceptions. SCI Nurs 1989; 6:44-7.

26. Ottomanelli L, Lind L. Review of critical factors related to employment after spinal cord injury: Implications for research and vocational services. J Spinal Cord Med 2009; 32:503-31.

27. Chapin $\mathrm{MH}$, Holbert D. Employment at closure is associated with enhanced quality of life and subjective well-being for persons with spinal cord injuries. Rehabil Couns Bull 2010; 54:6-14. doi: 10.1177/0034355210367685.

28. Groah SL, Nash MS, Ljungberg IH, Libin A, Hamm LF, Ward E, et al. Nutrient intake and body habitus after spinal cord injury: An analysis by sex and level of injury. J Spinal Cord Med 2009; 32:25-33.
29. Noreau L, Shephard RJ. Spinal cord injury, exercise and quality of life. Sports Med 1995; 20:226-50. doi: 10.2165/00007256199520040-00003.

30. Barker RN, Kendall MD, Amsters DI, Pershouse KJ, Haines TP, Kuipers P. The relationship between quality of life and disability across the lifespan for people with spinal cord injury. Spinal Cord 2009; 47:149-55. doi: 10.1038/sc.2008.82.

31. Ebrahimzadeh $\mathrm{MH}$, Soltani-Moghaddas SH, Birjandinejad A, Omidi-Kashani F, Bozorgnia S. Quality of life among veterans with chronic spinal cord injury and related variables. Arch Trauma Res 2014; 3:e17917. doi: 10.5812/atr.17917.

32. Saadat S, Javadi M, Divshali BS, Tavakoli AH, Ghodsi SM, Montazeri A, et al. Health-related quality of life among individuals with long-standing spinal cord injury: A comparative study of veterans and non-veterans. BMC Public Health 2010; 10:6. doi: 10.1186/1471-2458-10-6.

33. Hu Y, Mak JN, Wong YW, Leong JC, Luk KD. Quality of life of traumatic spinal cord injured patients in Hong Kong. J Rehabil Med 2008; 40:126-31. doi: 10.2340/16501977-0150.

34. Geyh S, Nick E, Stirnimann D, Ehrat S, Michel F, Peter C, et al. Self-efficacy and self-esteem as predictors of participation in spinal cord injury: An ICF-based study. Spinal Cord 2012; 50:699-706. doi: 10.1038/sc.2012.18.

35. Richards JS, Bombardier CH, Tate D, Dijkers M, Gordon W, Shewchuk R, et al. Access to the environment and life satisfaction after spinal cord injury. Arch Phys Med Rehabil 1999; 80:1501-6. doi: 10.1016/s0003-9993(99)90264-2.

36. Kreuter M, Siösteen A, Erkholm B, Byström U, Brown DJ. Health and quality of life of persons with spinal cord lesion in Australia and Sweden. Spinal Cord 2005; 43:123-9. doi: 10.1038/sj.sc.3101692.

37. Lude P, Kennedy P, Elfström ML, Ballert CS. Quality of life in and after spinal cord injury rehabilitation: A longitudinal multicenter study. Top Spinal Cord Inj Rehabil 2014; 20:197-207. doi: 10.1310/sci2003-197. 